\title{
Profits of public-private partnerships
}

Long-term, large-scale, scientific endeavors can generate considerable resource pools that can be used by an enormous number of people; they also require a generous amount of capital. One way to fulfill such financial needs is to develop partnerships between the public and private sectors, and the NIH Roadmap includes a section specificially aimed at doing just that. Such undertakings, however, were going on before the creation of this initiative and were part of the reason for its inclusion in the Roadmap.

The Mouse Sequencing Consortium is one project completed with money from both the NIH and industry. Another such effort is the Osteoarthritis Initiative, which has been in development since 1999. This program brings together public and private funding to build and carry out a seven-year project that will recruit 5,000 men and women over age 50 who are at high risk for developing osteoarthritis. The goal is to identify biological and structural markers for the progression and development of this disease.

Stephen Katz, Director of the National Institute of Arthritis and Musculoskeletal and Skin Disease, one of the leading institutes involved in this initiative, told the JCI, "This is a long-term project where we are going to follow individuals at high risk for developing some symptomatic knee osteoarthritis.” Researchers will take yearly biological samples, images, and clinical data from individuals enrolled in the study.

Four sites - the University of Maryland School of Medicine, Baltimore; The Ohio State University, Columbus; the University of Pittsburgh; and the Memorial Hospital of Rhode Island, Pawtucket - were selected in August of 2002 as the data collection centers, and the University of California, San Francisco, was designated the data coordination center. Each site will enroll 1250 adults; the first patients were recruited in February of this year.

"The beauty of this [program]," Katz said, "is that - like the genome or other projects that the NIH is looking to support - it is something that is going to be accessible to the world community as quickly as possible." Data will be released to the public 3 years, 4.5 years, and 7 years into the study.

The reason the data are released in chunks, Katz explained, is that "when you are developing data like this, it takes a while to validate it. We decided to start unfolding the information when we have 2500 individuals already registered for the study .. . If we do it on an individual basis, where [the data for] every individual is validated, then put out on the web, it wouldn't do anybody any good until you get a couple thousand people enrolled, and it would have been much, much more expensive."

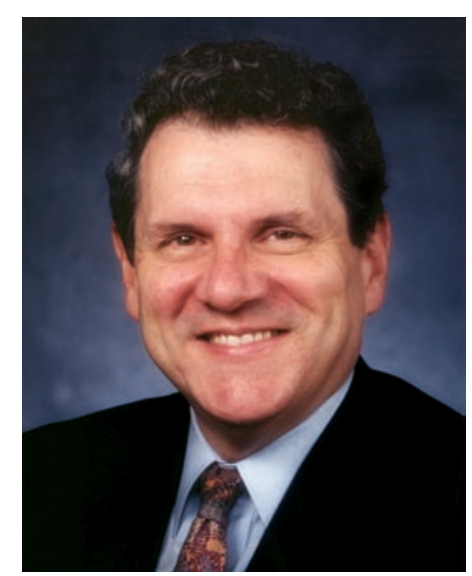

Stephen Katz emphasizes the partnership element in these endeavors.

Realizing a project of this type, however, requires more than just public money. To aid in developing public and private interactions, the Foundation for the National Institutes of Health, a not-for-profit organization, was established in 1996. Charles Pucie, Senior Advisor for Communications of the Foundation, told the JCI that the organization "was focused much more narrowly in its early conception, with fellowships and so forth. That changed dramatically in [the] middle 90s with the notion that we would work to support all sorts of activities of NIH across the board."

Pucie added, "For each of these major programs ... a model is developed for the administration and movement of information and for fiscal responsibilities that is pretty much unique to the particular program. This is because most of the partnerships that we have been involved in have been sui generis. In other words, the model for each of the partnerships has been [developed] to best suit the circumstances of the task at hand... And that certainly is true in the case of the Osteoarthritis Initiative."

Katz also noted that private institutions provide more than additional funding:
"There is a tremendous amount of intellectual capital in these pharmaceutical companies, and they really helped us in terms of identifying what some of the issues were."

Even with the aid of the Foundation, combining the needs of public and private institutions can be tricky. "It is a very delicate matter for the NIH to work with industry," Katz said. "We have to make sure that our goals are clearly defined ... if they are in alignment with the goals of industry, that's great. In this particular endeavor there is no advantage that these contributing companies have in terms of access to data."

Currently three companies, Merck Research Laboratories, Novartis Pharmaceuticals, and Pfizer Inc., support the initiative, contributing $\$ 800,000$ each annually. The total project cost is estimated to be \$55-60 million. But without early access to data or special rights to use any of the samples generated, why would any company get involved?

Katz believes there are a number of reasons. "They end up knowing what is going on to a much greater extent if they are involved. But I think they also realize that [it is] important ... for everyone to have some research resource that they can all tap into to validate what they themselves are doing on their own. It is a resource that is not going to be patentable, but if people utilize material from the resource and make discoveries, their discoveries are patentable."

Pucie added that "the broad thrust of the private funds is that it both accelerates a research project [and] allows for the adding of elements that might not otherwise have been feasible." Because these companies contribute to government-funded projects, the resultant resources will be more substantial and complete than the private or public sectors can develop working alone.

The current work on the Osteoarthritis Initiative and the past success of such joint ventures in the genome project are bolstering support for additional public-private partnerships, including one through the National Institute of Aging focusing on Alzheimer disease. While the future of these efforts remains unknown, these interactions appear to be giving everyone a leg up and will, it is hoped, ultimately benefit those suffering from these diseases.

\section{Laurie Goodman}

